\title{
Quality Indicators for the Prevention of Type 2 Diabetes in Europe - IMAGE
}

Authors

Affiliations
P. Pajunen $^{1}$, R. Landgraf ${ }^{2}$, F. Muylle ${ }^{3}$, A. Neumann ${ }^{4,5}$, J. Lindström ${ }^{1}$, P. E. Schwarz ${ }^{4}$, M. Peltonen ${ }^{1}$, for the IMAGE Study Group

* IMAGE Study Group: T. Acosta, M. Adler, A. AlKerwi, N. Barengo, R. Barengo, J. M. Boavida, K. Charlesworth, V. Christov, B. Claussen, X. Cos, E. Cosson, S. Deceukelier, V. Dimitrijevic-Sreckovic, P. Djordjevic, P. Evans, A.-M. Felton, M. Fischer,

R. Gabriel-Sanchez, A. Gilis-Januszewska, M. Goldfracht, J. L. Gomez, C. J. Greaves, M. Hall, U. Handke, H. Hauner, J. Herbst, N. Hermanns, L. Herrebrugh, C. Huber, U. Hühmer, J. Huttunen, A. Jotic, Z. Kamenov, S. Karadeniz, N. Katsilambros,

M. Khalangot, K. Kissimova-Skarbek, D. Köhler, V. Kopp, P. Kronsbein, B. Kulzer, D. Kyne-Grzebalski, K. Lalic, N. Lalic, R. Landgraf, Y. H. Lee-Barkey, S. Liatis, J. Lindström, K. Makrilakis, C. McIntosh, M. McKee, A. C. Mesquita, D. Misina, F. Muylle, A. Neumann, A. C. Paiva, P. Pajunen, B. Paulweber, M. Peltonen, L. Perrenoud, A. Pfeiffer, A. Pölönen, S. Puhl, F. Raposo, T. Reinehr,

A. Rissanen, C. Robinson, M. Roden, U. Rothe, T. Saaristo, J. Scholl, P. E. Schwarz, K. E. Sheppard, S. Spiers, T. Stemper,

B. Stratmann, J. Szendroedi, Z. Szybinski, T. Tankova, V. Telle-Hjellset, G. Terry, D. Tolks, F. Toti, J. Tuomilehto, A. Undeutsch,

C. Valadas, P. Valensi, D. Velickiene, P. Vermunt, R. Weiss, J. Wens, T. Yilmaz

The affiliations are listed at the end of the article

\section{Abstract \\ $\checkmark$}

Background: The marked increase of type 2 diabetes necessitates active development and implementation of efficient prevention programs. A European level action has been taken by launching the IMAGE project to unify and improve the various prevention management concepts, which currently exist within the EU. This report describes the background and the methods used in the development of the IMAGE project quality indicators for diabetes primary prevention programs. It is targeted to the persons responsible for diabetes prevention at different levels of the health care systems. Methods: Development of the quality indicators was conducted by a group of specialists representing different professional groups from several European countries. Indicators and measurement recommendations were

\section{Introduction}

\section{Bibliography}

DOI http://dx.doi.org/

10.1055/s-0029-1240976

Horm Metab Res 2010; 42

(Suppl. 1): S56-S63 @ Georg

Thieme Verlag KG Stuttgart.

New York · ISSN 0018-5043

Correspondence

Pia Pajunen

National Institute for Health and Welfare (THL)

P. O. Box 30

00271 Helsinki

Finland

Phone: + 358206106000

Fax: +358206108661

pia.pajunen@thl.fi produced by the expert group in consensus meetings and further developed by combining evidence and expert opinion. Results: The quality indicators were developed for different prevention strategies: population level prevention strategy, screening for high risk, and high risk prevention strategy. Totally, 22 quality indicators were generated. They constitute the minimum level of quality assurance recommended for diabetes prevention programs. In addition, 20 scientific evaluation indicators with measurement standards were produced. These micro level indicators describe measurements, which should be used if evaluation, reporting, and scientific analysis are planned. Conclusions: We hope that these quality tools together with the IMAGE guidelines will provide a useful tool for improving the quality of diabetes prevention in Europe and make different prevention approaches comparable.

weight [3-8]. Translating this evidence necessitates active development of efficient prevention strategies and programs [9]. To fulfil this need, European level action has been taken by launching the IMAGE project to unify and improve the various prevention management concepts, which currently exist within the EU. IMAGE stands for "Development and Implementation of a European Guideline and Training Standards for Diabetes Prevention" and it builds on the results of the EU public health research project DE-PLAN “Diabetes in Europe-Prevention using Lifestyle, Physical Activity and Nutritional Intervention", which relates to the efficient identification of individuals at high risk for type 2 diabetes in the community 
[10]. The objectives of the IMAGE project are: to develop an evidence-based consented European guideline for prevention of type 2 diabetes and a European curriculum and launch an ehealth training portal for the training of prevention managers (PM). Furthermore, the project aims to produce European standards for quality management for these interventions. These actions will form a unique European-wide evidence-based guidance system to systematically improve the prevention of type 2 diabetes in Europe [10].

Several projects aiming to enhance reporting related to diabetes have been conducted at the European level. The European Core Indicators for Diabetes Mellitus (EUCID) project (2006-2007) developed 27 indicators and demonstrated the feasibility of data collection in different EU countries and future member states. The aim of the project was to promote the planning for good diabetes health status and diabetes care organization in the different countries [11]. Many consortia have developed quality indicators specifically for clinical diabetes care. Despite recommendations, quality issues or indicators are not often incorporated into the clinical guidelines [12-16]. The OECD Quality Indicator Project has published a list of nine health system level quality indicators of diabetes care $[17,18]$. In the United States, the Diabetes Quality Improvement Project (DQIP) has developed and implemented a widely accepted and comprehensive set of national measures for evaluation [19]. A working group including participants from 15 EU/EFTA countries has generated an indicator set composed of 31 indicators for monitoring diabetes and its complications within EU/EFTA countries [20]. In several European countries efforts have been made to implement quality indicators in diabetes care. In Saxon, Germany, the Saxon Diabetes Management Programme has developed an integrated quality management system [21]. A Belgian study has produced a list of quality indicators for type 2 diabetes by evaluating 125 diabetes guidelines in five European countries [12]. One group from the Netherlands provided a set of quality indicators for pharmacological management of type 2 diabetes [22]. In the field of diabetes education, the International Diabetes Federation has published standards including quality indicators.

Continuous quality control and evaluation are the key elements of a successful primary prevention program, and thus, unified quality standards are necessary for systematical evaluation and reporting of the prevention programs in the EU and on national levels [10]. Currently, diabetes prevention programs often lack methods for systematical follow-up and evaluation and there are no standardized European level quality indicators for diabetes prevention. This report describes the background and the methods used in the development of the quality tools in the IMAGE project, and present the European quality indicators for diabetes primary prevention programs. This report also focuses on primary prevention and is targeted to the persons responsible for diabetes prevention at different levels of the health care system.

\section{Methodology \\ $\nabla$}

\section{Process of developing indicators}

Development of the IMAGE quality management system including quality indicators was conducted by a group of specialists representing different professional groups from several European countries. Members of the group have been actively involved in the pivotal studies on diabetes prevention such as the Diabetes Prevention Study (DPS) [3] and have extensive experience in im- plementation of the diabetes prevention programs within the community.

The development of the quality management processes and quality indicators was based on combining evidence and expert opinion. Indicators were produced by the expert group in consensus meetings and further developed by a subgroup of experts. The working group reviewed the existing scientific evidence in the field. Based on that knowledge, measurement specifications were designed and the standards of the indicator described. Initially, 109 quality indicators were developed. Further selection revealed 22 quality indicators. In addition, 20 scientific outcome evaluation indicators were developed. This process included detailed group discussions and additional literature surveys. The final approval and selection of the indicators were performed with a stepwise approval process in which the participants of the other IMAGE working groups gave their comments on the quality indicators before final selection.

\section{Defining target population}

The IMAGE quality indicators are presented separately for population level and high risk prevention strategies as well as for screening for high risk. The population level prevention strategy aims to improve, develop, and implement primary prevention programs and activities targeting the entire population. From a societal perspective, this is not the sole responsibility of the health care sector. Successful population level prevention of diabetes involves the participation of different community stakeholders such as decision makers, educational system, food industry, media, urban planning, and nongovernmental organizations. Screening for individuals at high risk for type 2 diabetes is essential for successful interventions. Different methods to screen for high risk individuals include the use of risk questionnaires, opportunistic screening, and computer database searching. Each country and organization has to develop and introduce a method suitable for its local needs and resources.

Clinical studies have consistently shown that diabetes can be prevented or at least postponed by lifestyle changes related to healthy nutrition, adequate amount of physical exercise, and weight reduction [3-8]. In addition to lifestyle changes, drugs such as metformin, acarbose, orlistat, and thiazolidinediones can reduce the relative risk of diabetes in high risk individuals with impaired glucose tolerance [5,7,25-29]. The aim of the high risk prevention strategy is to identify high risk individuals and support them with life-style changes required to reduce their risk for diabetes and other vascular risk factors.

The quality indicators were generated to be applicable to the broadest possible population. The definition of high risk population used here covers all subjects at risk for type 2 diabetes irrespective of the screening method used to identify these individuals. They are designed for adults, but not restricted to any specific age group within the adult population, and are applicable to both genders, but may not be applicable to different ethnic groups.

\section{Classification of indicators}

Structure, process, outcome model

The quality assessment theory by Donabedian is called the structure/process/outcome (SPO) or the Donabedian's Triad Model [30,31]. This theory comprises three quality elements: structure, process, and outcome. Structure describes the material and human resources as well as the organizational structure. This includes facilities, financing, equipment, and personnel. Process relates to activities undertaken to achieve objectives such as ac- 
tivities related to giving and receiving care or implementing interventions. Outcome describes the effect of care or interventions on the health status of a subject or population.

The IMAGE quality indicators are classified according to the structure/process/outcome (SPO) model $[30,31]$ modified so that, for practical reasons, combined structure/process indicators are presented. The structure/process indicators constitute the quality criteria for diabetes prevention and the outcome indicators focus on outcome evaluation and monitoring. Thus, indicators belong either to structure/process or outcome categories. The latter include both intermediate and end-result indicators as appropriate for the setting. Intermediate outcome indicators reflect changes in biological status and may be regarded as short-term outcomes [32].

\section{Macro, meso and micro levels}

Indicators are meant for users operating at different levels of the health care system. At the macro level, indicators are developed to be utilized by national level decision makers generating the prerequisite for diabetes/obesity prevention. This means, for example, representatives of the national level health institutes or nongovernmental organizations.

The level of operative primary health care providers is called the meso level. Depending on the country, indicators may be used by individuals responsible for activities on diabetes prevention in municipalities, health districts, health care centers, occupational care, private sector, or local level nongovernmental organizations.

At the micro level, the indicators are meant for use by the personnel who execute the actual preventive work. This may be a physician, nurse, dietician, physiotherapist, or prevention manager.

The IMAGE quality indicators are categorized so that the population level prevention strategy indicators include macro and meso level indicators, screening for high risk indicators are applicable to meso level, and the high risk prevention strategy indicators for meso and micro levels.

\section{Quality and scientific outcome evaluation indicators}

The IMAGE indicators are divided into quality and scientific outcome evaluation indicators. Quality indicators are the minimum requirement to be taken into account when conducting prevention activities depending on the level of operator. An additional set of indicators, scientific outcome evaluation indicators, is provided for scientific evaluation purposes. Further, measurement standards for scientific outcome evaluation are provided.

\section{Results}

$\nabla$

\section{Quality indicators for diabetes prevention}

Population level prevention strategy

At the macro level, a prerequisite for desired outcome in the population level prevention strategy is that policies and legislation support an environment favoring diabetes prevention. In addition, each country should have a national diabetes prevention plan in which specific prevention targets are defined. These targets should include consideration of the special needs of ethnic minorities and underprivileged socio-economic groups. Furthermore, policies and legislation should take into account specific measures needed for the prevention of obesity among children and adolescent. To enable these tasks, the national health moni- toring systems should provide sufficient information for conducting efficient surveillance.

At the health care provider level, processes should support health promotion including diabetes prevention. The health care provider should allocate sufficient resources to the preventive work. Basic knowledge on population level prevention of diabetes/obesity/cardiovascular diseases should be included in the curricula of the medical professionals working for the health care provider. Collaboration between different stakeholders active in the health promotion field should be effective.

In addition to the above mentioned quality criteria on structure and process, a list of outcome indicators were generated during the course of the IMAGE work ( $\odot$ Table 1, upper panel). With these indicators at hand, decision makers can monitor and evaluate the quality and effectiveness of the selected population level strategies.

\section{Screening for high risk}

Screening is an essential part of the high risk prevention strategy. In addition, screening protocols can be designed so that they support also population level prevention activities by increasing the awareness of the disease. Different screening protocols should be validated and evaluated at national level. The selected protocols and strategies should be implemented by the health care provider. The employed screening protocol should contain a pathway for diagnostic procedures, as well as defined intervention strategies for the different subgroups (age, minorities etc.). The health care provider should promote validated diabetes risk assessment tools. Information technology systems should support the implementation of screening.

Depending on the health care system, these indicators can be the responsibility of either macro- or meso levels of operators. In addition, the indicators in $\odot$ Table 1, middle panel, were identified as outcome indicators for screening for high risk.

\section{High risk prevention strategy}

At meso level, every screening strategy should incorporate clinical pathways at the health care provider organization to deal with individuals at risk for diabetes. The health care provider should support a multidisciplinary approach for interventions. High risk prevention strategies should be included in the education of the healthcare professionals. The medical record system should support interventions and chronic disease prevention in general.

At micro level, the individual's risk factor profile should be assessed in the beginning of the intervention process, and the motivation for behavioral changes explored. Structure and content of the interventions should be defined and individualized targets for interventions established. A plan for individual follow-up should be defined and recorded. The indicators in $\odot$ Table 1, lower panel, were identified as outcome indicators at meso and micro levels.

In addition to the quality indicators related to the high risk intervention strategy at micro level, target values which correspond to the indicators were identified. In the DPS study [3], the following targets were applied: weight reduction $5 \%$ or more, moderate intensity physical activity 30 minutes daily or more, dietary fat less than $30 \mathrm{E} \%$, saturated fat less than $10 \mathrm{E} \%$, intake of fiber $15 \mathrm{~g} / 1000$ $\mathrm{kcal}(15 \mathrm{~g} / 4200 \mathrm{KJ})$ or more. These targets may be taken into consideration when planning micro level diabetes prevention. However, intervention targets should be individualized based on the baseline evaluation. 


\section{Population level prevention strategy}

Proportion of population aware of diabetes and its risk factors

Prevalence of diabetes in the population

Percentage of the population physically inactive

Prevalence of overweight, obesity, and abdominal obesity in population

Percentage of population following national recommendations on nutrition

Percentage of health care costs allocated to prevention programs

Proportion of health care personnel per health care provider active in population level primary prevention

Number of health promotion organizations active in population level primary prevention

\section{Screening for high risk}

Proportion of the population screened by health care providers per year

The percentage of identified high risk individuals directed to diagnostic procedures

The percentage of identified high risk individuals directed to lifestyle interventions

\section{High risk prevention strategy}

Number of healthcare professionals at health care provider level qualified for interventions per

100000 inhabitants

The percentage of remitted high risk individuals participating in lifestyle interventions

Proportion of individuals dropping out of interventions

Proportion of high risk individuals in interventions achieving clinically significant changes in risk factors at

1 year follow-up

Diabetes incidence rate among high risk individuals in interventions

Proportion of planned intervention visits completed over 1 year

Weight change over 1 year

Change in waist circumference over 1 year

Change in glucose over 1 year

Change in the quality of nutrition over 1 year

Change in physical activity over 1 year
Level

Macro

Macro

Macro

Macro

Macro

Macro

Meso

Meso

Meso

Meso

Meso

Meso

Meso

Meso

Meso

Meso

Micro

Micro

Micro

Micro

Micro

Micro
Table 1 Outcome quality indicators for a population level prevention strategy, screening for high risk, and high risk prevention strategies

\begin{tabular}{lll}
\hline Indicator & Unit & Reference \\
\hline Body weight & $\mathrm{kg}$ & FEHES [38], WHO STEPS [39] \\
\hline BMI & $\mathrm{kg} / \mathrm{m}^{2}$ & FEHES [38], WHO STEPS [39] \\
\hline Waist circumference & $\mathrm{cm}$ & FEHES [38], WHO STEPS [39] \\
\hline Fasting and 2-hour OGTT glucose & $\mathrm{mmol} / \mathrm{I}$ & WHO [33, 34,40] \\
\hline HbA1c & $\%$ & IFCC [23, 24] \\
\hline Fasting insulin & $\mathrm{mU} / \mathrm{I}$ & IFCC [41] \\
\hline Total energy intake & $\mathrm{kcal} /$ day & IMAGE Toolkit [42, 43] \\
\hline Fat intake & E\% & IMAGE Toolkit [42, 43] \\
\hline Saturated fat intake & E\% & IMAGE Toolkit [42,43] \\
\hline Fiber intake & $\mathrm{g} / 1000 \mathrm{kcal}$ & IMAGE Toolkit [42, 43] \\
\hline Physical activity & $\mathrm{METS}$ & [35, 44-48] \\
\hline Fasting total, HDL, and LDL cholesterol cholesterol & $\mathrm{mmol} / \mathrm{I}$ & FEHES [38], CDC [49] \\
\hline Fasting triglycerides & $\mathrm{mmol} / \mathrm{I}$ & FEHES [38], CDC [49] \\
\hline Systolic and diastolic blood pressure & $\mathrm{mmHg}$ & FEHES [38], WHO STEPS [39] \\
\hline Smoking habits & & FEHES [38] \\
\hline Drug treatments & & EHIS [50] \\
\hline Costs & $€$ & IMAGE Evidence-Based Guidelines \\
\hline Quality of life & Score & WHO-5 [51], SF-36 [52], SF-12 [53] 15-D [54] \\
\hline Treatment satisfaction & Score & DTSQ [55] \\
\hline
\end{tabular}

\section{Scientific outcome evaluation indicators for diabetes prevention}

- Table 2 presents the recommended scientific evaluation indicators to be used as outcome measures in scientific evaluation of a diabetes prevention program.

To obtain reliable results, measurements and methods used in the diabetes prevention programs should be standardized and valid. OTable 2 provides the references for the recommended measurement protocols for the scientific outcome evaluation indicators.
The standards related to physical measurements (weight, height, waist circumference, blood pressure) can be found from the Feasibility of European Health Examination Survey (FEHES) recommendations [38] and from the World Health Organization (WHO), STEPS Manual [39]. The FEHES recommendations include also a questionnaire on smoking habits.

Recommendations on blood sampling and lipid measurements are available in the FEHES recommendations and in the U.S. Center for Disease Control and Prevention (CDC) which has a certification program for lipid measurements [49]. 
The WHO Laboratory Diagnosis and Monitoring of Diabetes Mellitus 2002 document provides standards for glucose measurements including the oral glucose tolerance test (OGTT) [40]. Diagnosis of diabetes and risk assessment is based on fixed cutoff points. For this reason all steps in the analytical process require attention [33]. It is important to notice that preanalytical issues may seriously affect the quality of the glucose assays. Glucose is lost through glycolysis and $\mathrm{NaF}$ has been used for decades to inhibit glycolysis. In addition, ice slurry is often used to prevent preanalytic loss of glucose. However, new Fluorid-Citrate-mixture tubes allow prolonged storage and transport of the samples and should be considered to assure a high quality measurement process [33,34]. Even though this is expected to improve the precision of glucose measurements, it may increase the number of individuals diagnosed with diabetes unless compensatory changes in diagnostic cutoff points are made [33].

The International Federation of Clinical Chemistry and Laboratory Medicine (IFCC) has published standards for HbA1c measurements [23,24]. Major differences exist in commercially available insulin assays. An IFCC working group on the Standardization of Insulin Assays has been jointly established with the American Diabetes Association and is currently developing a candidate reference method for insulin analysis.

There is no consensus on what constitutes adequate measurement and documentation of physical activity or nutrition. Dietary pattern and composition can be evaluated with several methods: food diary, food frequency questionnaire, and checklist. The selection of a method depends on availability, cultural background, and resources and cooperativeness of a high risk person. For accurate calculation of nutrient intakes, culturally specific food composition databases are mandatory. The quality of diet in relation to recommendations and dietary changes can also be assessed based on frequency of consumption of recommendable (e.g., vegetables, fruit, whole grain) and nonrecommendable (e.g., soft drinks, pastries) food items.

Accurate methods to measure physical activity are pedometers and accelerometers. Self-reported data can be collected via interviews, diaries, and recalls. Assessing physical activity should include: type of activity (e.g., walking, swimming), frequency (number of sessions), duration, and intensity (level of physical effort). Using these four components, relative energy expenditure can be estimated, often referred to metabolic equivalents, METS [35].

The European Health Interview Survey (EHIS) includes standardized questions on use of medications [50]. Issues related to health economic evaluation and the costs are presented in the IMAGE Scientific Guidelines. Quality of life should be measured with standardized instruments and possible translations should be certified. Treatment satisfaction can be measured for example with the Diabetes Treatment Satisfaction Questionnaire: DTSQ [55].

\section{Micro level data collection form}

The data items presented in 0 Table $\mathbf{3}$ are an example of the content that is recommended to be included and adapted into the local version of the data collection tools at the micro level diabetes prevention. However, the local needs and circumstances are decisive for the final form of the data collection form applied in different prevention programs.

\section{Discussion}

$\nabla$

As part of the IMAGE project, a set of quality and scientific outcome evaluation indicators for diabetes prevention programs were developed together with the development of the IMAGE evidence-based guideline and the accompanying practical guide for prevention. Therefore, the indicators are closely linked to the guideline standards and are meant to be used in conjunction with the guidelines. The quality indicators are intended to provide European decision makers, health care providers, and health care personnel working with prevention activities the tools to monitor, evaluate and improve the quality of diabetes prevention. In addition, standards of measurements for scientific outcome indicator were identified, aiming to report about the clinical trials and effectiveness research across Europe, enabling comparisons between different study groups.

Both individual and population level prevention strategies were taken into account when developing the indicators. The quality indicators were selected to represent different dimensions of preventive work: population level prevention strategy, screening for high risk, and high risk prevention strategy. To promote the usability of the indicators, they were generated to be applicable to the broadest possible population. The definition of high risk population used covers all subjects at risk for type 2 diabetes irrespective of the screening method used in identifying the individuals.

Some of the macro level outcome indicators require data that can only be obtained through population-based health surveys. The Feasibility of a European Health Examination Survey (FEHES) collaboration [36], another EU-funded project provides recommendations for organizing standardized health surveys. Further, population level standardized data may be available in the future through the EUBIROD collaboration [37].

The quality indicators are intended to be used in prospective settings, but may be applicable for retrospective analysis if the quality of data collection enables this. They comprise the minimum level of quality standards. Individuals and organizations using these measures are spurred to involve the scientific evaluation perspective into the preventive work by using the scientific outcome evaluation indicators and related instruments described in the measurement standards section. High quality methodology is essential to attain reliable and comparable results.

As the responsibility of the implementation of the guidelines differs depending on the national and local legislation, the implementation of the guidelines may need adaptation to local regulations and circumstances. At the micro level, individual targets should be based on individualized baseline evaluation.

Even though data from the pivotal diabetes prevention studies have proved the effect of preventive interventions, less data are available on the effectiveness of implementing diabetes prevention into everyday work in primary health care outside of prospective RCTs. Thus, the development of the quality management processes and quality indicators was based on combining evidence and expert opinion. Some limitations related to the development process should be noticed.

Even though the quality indicators are linked to the IMAGE scientific guidelines data standards, target value assignment was difficult because of lack of data on the general population. It should be noticed that target values related to weight reduction, nutrition, and physical activity for micro level quality indicators are drawn from the DPS Study, which was conducted in obese individuals with impaired glucose tolerance. 


\begin{tabular}{|c|c|c|}
\hline & Core items & Additional items \\
\hline \multicolumn{3}{|l|}{ Personal data } \\
\hline & Personal identification & Marital status \\
\hline & & Education \\
\hline & & Ethnicity \\
\hline & & Employment status \\
\hline \multicolumn{3}{|l|}{ Screening } \\
\hline & Method used in screening & \\
\hline & Risk score type and result (if used) & \\
\hline & Reason for intervention & \\
\hline \multicolumn{3}{|c|}{ Health and health behavior } \\
\hline & Chronic diseases & Family history of diabetes and CVD \\
\hline & Regular medications & \\
\hline & Smoking: & \\
\hline & - never/previously/currently & - how often, products used \\
\hline & Physical activity: & \\
\hline & - type, frequency, intensity & - work-related, commuting, leisure \\
\hline & $\begin{array}{l}\text { method used in measuring (e.g., interview, diary, } \\
\text { recall, pedometers, accelerometers) }\end{array}$ & \\
\hline & Nutrition: & \\
\hline & $\begin{array}{l}\text { dietary pattern: for example, consumption of } \\
\text { vegetables, fruits, spreads and oil, bread and } \\
\text { cereal (whole/refined grain), sweets, beverages, } \\
\text { alcohol }\end{array}$ & $\begin{array}{l}\text { energy proportion (E\%) of fat, saturated and } \\
\text { trans fat, dietary fiber (g/day, g/1000 kcal), total } \\
\text { energy, alcohol (g, E\%), added sugar ( } \mathrm{g}, \mathrm{E} \% \text { ) }\end{array}$ \\
\hline & $\begin{array}{l}\text { method used in measuring (e.g., food diary, food } \\
\text { frequency questionnaire or checklist) }\end{array}$ & \\
\hline \multicolumn{3}{|c|}{ Clinical data (measured) } \\
\hline & Body weight & 2-hour OGTT glucose \\
\hline & Body height & HbA1c \\
\hline & Waist circumference & Lipids (total, LDL, HDL cholesterol, and triglycerides) \\
\hline & Fasting glucose & Additional measures (fasting insulin, etc) \\
\hline & Systolic and diastolic blood pressure & \\
\hline \multicolumn{3}{|c|}{ Content of the intervention } \\
\hline & Type of intervention (group, individual, etc.) & \\
\hline & Frequency, duration and other details & \\
\hline & Targets for the intervention: & \\
\hline & - weight, diet, smoking, physical activity & \\
\hline & Reinforcement & \\
\hline \multicolumn{3}{|c|}{ Success of the intervention } \\
\hline & $\begin{array}{l}\text { Adherence (proportion of planned intervention } \\
\text { visits completed) }\end{array}$ & $\begin{array}{l}\text { The Diabetes Treatment Satisfaction Questionnaire: } \\
\text { DTSQ }\end{array}$ \\
\hline & $\begin{array}{l}\text { Changes in: health and health behavior } \\
\text { and clinical data }\end{array}$ & Health related quality of life \\
\hline \multicolumn{3}{|l|}{ Maintenance } \\
\hline & $\begin{array}{l}\text { Plans how to sustain possible lifestyle changes } \\
\text { after intervention }\end{array}$ & \\
\hline
\end{tabular}

Table 3 Recommended contents to be included and adapted in the local versions of the data collection forms to support, monitor, and evaluate micro level diabetes prevention
In conclusion, parallel with the development of the IMAGE guidelines for the prevention of type 2 diabetes, a quality management system with quality and scientific outcome evaluation indicators were developed. The indicators are presented by different levels of the health care system. They can be used for internal quality control, as well as for external comparison between operators. These quality tools complement the IMAGE guidelines and the prevention manager curriculum, and will provide a useful tool for improving the quality of diabetes prevention in Europe.

\section{Affiliations}

${ }^{1}$ Diabetes Prevention Unit, Department of Chronic Disease Prevention,

National Institute for Health and Welfare, Helsinki, Finland

${ }^{2}$ German Diabetes Foundation, Munich, Germany

3 Vlaamse Diabetes Vereniging vzw, Gent, Belgium

${ }^{4}$ Carl Gustav Carus Medical Faculty, Technical University of Dresden,

Dresden, Germany

${ }^{5}$ Department of Public Health and Clinical Medicine, Umeå University, Umeå, Sweden 


\section{References}

1 Wild S, Roglic G, Green A, Sicree R, King H. Global prevalence of diabetes: estimates for the year 2000 and projections for 2030. Diabetes Care 2004; 27: 1047-1053

2 IDF. IDF Diabetes Atlas, 2009. [updated 2009; cited October 21, 2009] Available from: http://www.diabetesatlas.org/

3 Tuomilehto J, Lindström J, Eriksson JG, Valle TT, Hämäläinen H, IlanneParikka P, Keinänen-Kiukaanniemi S, Laakso M, Louheranta A, Rastas $M$, Salminen $V$, Uusitupa M. Prevention of type 2 diabetes mellitus by changes in lifestyle among subjects with impaired glucose tolerance. N Engl J Med 2001; 344: 1343-1350

4 Lindström J, Ilanne-Parikka P, Peltonen M, Aunola S, Eriksson JG, Hemio $K$, Hämäläinen $H$, Härkönen P, Keinänen-Kiukaanniemi S, Laakso M, Louheranta A, Mannelin M, Paturi M, Sundvall J, Valle TT, Uusitupa M, Tuomilehto J. Sustained reduction in the incidence of type 2 diabetes by lifestyle intervention: follow-up of the Finnish Diabetes Prevention Study. Lancet 2006; 368: 1673-1679

5 Knowler WC, Barrett-Connor E, Fowler SE, Hamman RF, Lachin JM, Walker EA, Nathan DM. Reduction in the incidence of type 2 diabetes with lifestyle intervention or metformin. N Engl J Med 2002; 346: 393-403

6 Li G, Zhang P, Wang J, Gregg EW, Yang W, Gong $Q$ Li H, Jiang Y, An Y, Shuai Y, Zhang B, Zhang J, Thompson TJ, Gerzoff RB, Roglic G, Hu Y, Bennett $P H$. The long-term effect of lifestyle interventions to prevent diabetes in the China Da Qing Diabetes Prevention Study: a 20-year follow-up study. Lancet 2008; 371: 1783-1789

7 Ramachandran A, Snehalatha C, Mary S, Mukesh B, Bhaskar AD, Vijay V. The Indian Diabetes Prevention Programme shows that lifestyle modification and metformin prevent type 2 diabetes in Asian Indian subjects with impaired glucose tolerance (IDPP-1). Diabetologia 2006; 49: 289-297

8 Kosaka K, Noda M, Kuzuya T. Prevention of type 2 diabetes by lifestyle intervention: a Japanese trial in IGT males. Diabetes Res Clin Pract 2005; 67: 152-162

9 Schwarz PE, Schwarz J, Schuppenies A, Bornstein SR, Schulze J. Development of a diabetes prevention management program for clinical practice. Public Health Rep 2007; 122: 258-263

10 Schwarz PE, Gruhl U, Bornstein SR, Landgraf R, Hall M, Tuomilehto J. The European perspective on diabetes prevention: development and Implementation of A European Guideline and training standards for diabetes prevention (IMAGE). Diab Vasc Dis Res 2007; 4: 353-357

11 EUCID. Final report European Core Indicators in Diabetes project, 2008. [updated 2008; cited October 21, 2009] Available from: http:// ec.europa.eu/health/ph_projects/2005/action1/docs/action1_2005_ frep_11_en.pdf

12 Wens J, Dirven K, Mathieu C, Paulus D, Van Royen P. Quality indicators for type-2 diabetes care in practice guidelines: an example from six European countries. Prim Care Diabetes 2007; 1: 17-23

13 IDF. Global Guideline for Type 2 Diabetes: recommendations for standard, comprehensive, and minimal care. Diabet Med 2006; 23: 579593

14 Ryden L, Standl E, Bartnik M, Van den Berghe G, Betteridge J, de Boer MJ, Cosentino F, Jonsson B, Laakso M, Malmberg K, Priori S, Ostergren J, Tuomilehto J, Thrainsdottir I, Vanhorebeek I, Stramba-Badiale M, Lindgren P, Oiao Q Priori SG, Blanc IJ, Budaj A, Camm J, Dean V, Deckers J, Dickstein K, Lekakis J, McGregor K, Metra M, Morais J, Osterspey A, Tamargo J, Zamorano JL, Deckers JW, Bertrand M, Charbonnel B, Erdmann E, Ferrannini E, Flyvbjerg A, Gohlke H, Juanatey JR, Graham I, Monteiro PF, Parhofer $K$, Pyorala K, Raz I, Schernthaner G, Volpe M, Wood D. Guidelines on diabetes, pre-diabetes, and cardiovascular diseases: executive summary. The Task Force on Diabetes and Cardiovascular Diseases of the European Society of Cardiology (ESC) and of the European Association for the Study of Diabetes (EASD). Eur Heart J 2007; 28: 88-136

15 Buse JB, Ginsberg HN, Bakris GL, Clark NG, Costa F, Eckel R, Fonseca V, Gerstein HC, Grundy S, Nesto RW, Pignone MP, Plutzky J, Porte D, Redberg $R$, Stitzel KF, Stone NJ. Primary prevention of cardiovascular diseases in people with diabetes mellitus: a scientific statement from the American Heart Association and the American Diabetes Association. Circulation 2007; 115: 114-126

16 Graham I, Atar D, Borch-Johnsen K, Boysen G, Burell G, Cifkova R, Dallongeville J, De Backer G, Ebrahim S, Gjelsvik B, Herrmann-Lingen C, Hoes A, Humphries S, Knapton M, Perk J, Priori SG, Pyorala K, Reiner Z, Ruilope L, Sans-Menendez S, Op Reimer WS, Weissberg P, Wood D, Yarnell J, Zamorano JL, Walma E, Fitzgerald T, Cooney MT, Dudina A, Vahanian A, Camm J, De Caterina R, Dean V, Dickstein K, Funck-Brentano C, Filippatos G, Hel- lemans I, Kristensen SD, McGregor K, Sechtem U, Silber S, Tendera M, Widimsky P, Altiner A, Bonora E, Durrington PN, Fagard R, Giampaoli S, Hemingway H, Hakansson J, Kjeldsen SE, Larsen L, Mancia G, Manolis AJ, Orth-Gomer K, Pedersen T, Rayner M, Ryden L, Sammut M, Schneiderman N, Stalenhoef AF, Tokgozoglu L, Wiklund O, Zampelas A. European guidelines on cardiovascular disease prevention in clinical practice: full text. Fourth Joint Task Force of the European Society of Cardiology and other societies on cardiovascular disease prevention in clinical practice (constituted by representatives of nine societies and by invited experts). Eur J Cardiovasc Prev Rehabil 2007; 14 (Suppl. 2): S1S113

17 Greenfield S, Nicolucci A, Mattke S. Selecting indicators for the quality of diabetes care at the health system level in OECD countries. Paris: OECD Health Technical Papers; 2004

18 Nicolucci A, Greenfield S, Mattke S. Selecting indicators for the quality of diabetes care at the health systems level in OECD countries. Int J Qual Health Care 2006; 18 (Suppl. 1): 26-30

19 Fleming BB, Greenfield S, Engelgau MM, Pogach LM, Clauser SB, Parrott $M A$. The Diabetes Quality Improvement Project: moving science into health policy to gain an edge on the diabetes epidemic. Diabetes Care 2001; $24: 1815-1820$

20 de Beaufort CE, Reunanen A, Raleigh V, Storms F, Kleinebreil L, Gallego $R$, Giorda C, Midthjell K, Jecht M, de Leeuw I, Schober E, Boran G, Tolis G. European Union diabetes indicators: fact or fiction? Eur J Public Health 2003; $13: 51-54$

21 Rothe U, Muller G, Schwarz PE, Seifert M, Kunath H, Koch R, Bergmann S, Julius U, Bornstein SR, Hanefeld M, Schulze J. Evaluation of a diabetes management system based on practice guidelines, integrated care, and continuous quality management in a Federal State of Germany: a population-based approach to health care research. Diabetes Care 2008; 31: 863-868

22 Martirosyan L, Braspenning J, Denig P, de Grauw WJ, Bouma M, Storms F, Haaijer-Ruskamp FM. Prescribing quality indicators of type 2 diabetes mellitus ambulatory care. Qual Saf Health Care 2008; 17: 318-323

23 Anonymous. Consensus statement on the worldwide standardisation of the HbA1c measurement. Diabetologia 2007; 50: 2042-2043

24 Anonymous. Implementation of standardization of HbA1c measurement. Summary of the meeting with manufacturers held in Milan, Italy, December 12, 2007. Clin Chem Lab Med 2008; 46: 573-574

25 Gillies CL, Abrams KR, Lambert PC, Cooper NJ, Sutton AJ, Hsu RT, Khunti K. Pharmacological and lifestyle interventions to prevent or delay type 2 diabetes in people with impaired glucose tolerance: systematic review and meta-analysis. BMJ 2007; 334: 299

26 Chiasson JL, Josse RG, Gomis R, Hanefeld M, Karasik A, Laakso M. Acarbose treatment and the risk of cardiovascular disease and hypertension in patients with impaired glucose tolerance: the STOP-NIDDM trial. JAMA 2003; 290: 486-494

27 Richelsen B, Tonstad S, Rossner S, Toubro S, Niskanen L, Madsbad S, Mustajoki P, Rissanen A. Effect of orlistat on weight regain and cardiovascular risk factors following a very-low-energy diet in abdominally obese patients: a 3-year randomized, placebo-controlled study. Diabetes Care 2007; 30: 27-32

28 Torgerson JS, Hauptman J, Boldrin MN, Sjöström L. XENical in the prevention of diabetes in obese subjects (XENDOS) study: a randomized study of orlistat as an adjunct to lifestyle changes for the prevention of type 2 diabetes in obese patients. Diabetes Care 2004; 27: 155-161

29 Defronzo RA, Banerji M, Bray GA, Buchanan TA, Clement S, Henry RR, Kitabchi AE, Mudaliar S, Musi N, Ratner R, Reaven PD, Schwenke D, Stentz $F B$, Tripathy D. Actos Now for the prevention of diabetes (ACT NOW) study. BMC Endocr Disord 2009; 9: 17

30 Donabedian A. Evaluating the quality of medical care. Milbank Mem Fund Q 1966; 44 (Suppl.): 166-206

31 Donabedian A. The quality of care. How can it be assessed? JAMA 1988; 260: $1743-1748$

32 Mainz J. Developing evidence-based clinical indicators: a state of the art methods primer. Int J Qual Health Care 2003; 15 (Suppl. 1): i5-i11

33 Bruns DE, Knowler WC. Stabilization of glucose in blood samples: why it matters. Clin Chem 2009; 55: 850-852

34 Gambino R, Piscitelli J, Ackattupathil TA, Theriault JL, Andrin RD, Sanfilippo ML, Etienne M. Acidification of blood is superior to sodium fluoride alone as an inhibitor of glycolysis. Clin Chem 2009; 55: 1019-1021

35 Kriska A, Caspersen C. Introduction to a collection of physical activity questionnaires. Med Sci Sports Exerc 1997; 29 (Suppl. 6): S5-S9

36 Feasibility of a European Health Examination Survey (FEHES) project. [cited November 3, 2009] Available from: http://www.ktl.fi/fehes/ 
37 EUBIROD. EUropean Best Information through Regional Outcomes in Diabetes. [cited October 27, 2009] Available from: http://www. eubirod.eu/home.htm

38 Tolonen H, Koponen P, Aromaa A, Conti S, Graff-Iversen S, Grotvedt L, Kanieff M, Mindell J, Natunen S, Kuulasmaa K; for the feasibility of a European Health Examination Survey (FEHES) Project. Recommendations for the Health Examination Surveys in Europe, 2009. [updated 2009; cited October 21, 2009] Available from: http://www.ktl.fi/attachments/ suomi/julkaisut/julkaisusarja_b/2008/2008b21.pdf

39 WHO. STEPwise approach to surveillance (STEPS). Part 3: Training and Practical Guides 3-3-14. Section 3: Guide to Physical Measurements (Step 2) 2008. [updated 2008; cited October 21, 2009] Available from: http://www.who.int/chp/steps/Part3_Section3.pdf

40 WHO. Laboratory Diagnosis and Monitoring of Diabetes Mellitus 2002. [updated 2002; cited October 21, 2009] Available from: http:// whqlibdoc.who.int/hq/2002/9241590483.pdf

41 IFCC. Standardization of Insulin Assays (WG-SIA), in collaboration with ADA/EASD. [cited October 21, 2009] Available from: http://ifcc. nassaro.com/index.asp?cat=Scientific_Activities\&scat=Working_ Groups\&suba=Standardization_of_Insulin_Assays_\%28WG-SIA\%29 \&zip $=1 \&$ dove $=1$ \& numero $=70$

42 Block G. Human dietary assessment: methods and issues. Prev Med 1989; 18: 653-660

43 Willett W. Nutritional epidemiology, 2nd edition. New York: Oxford University Press; 1998

44 Paffenbarger Jr RS, Blair SN, Lee IM, Hyde RT. Measurement of physical activity to assess health effects in free-living populations. Med Sci Sports Exerc 1993; 25: 60-70

45 Lakka TA, Salonen JT. Intra-person variability of various physical activity assessments in the Kuopio Ischaemic Heart Disease Risk Factor Study. Int J Epidemiol 1992; 21: 467-472
46 Lakka TA, Venöläinen JM, Rauramaa R, Salonen R, Tuomilehto J, Salonen $J T$. Relation of leisure-time physical activity and cardiorespiratory fitness to the risk of acute myocardial infarction. N Engl J Med 1994; 330: $1549-1554$

47 Lindström J, Louheranta A, Mannelin M, Rastas M, Salminen V, Eriksson J, Uusitupa M, Tuomilehto J. The Finnish Diabetes Prevention Study (DPS): Lifestyle intervention and 3-year results on diet and physical activity. Diabetes Care 2003; 26: 3230-3236

48 IPAQ. The International Physical Activity Questionnaires (IPAQ). [cited October 21, 2009] Available from: http://www.ipaq.ki.se/ipaq.htm

49 CDC. The Cholesterol Reference Method Laboratory Network (CRMLN). [cited October 21, 2009] Available from: http://www.cdc.gov/labstandards/crmln.htm

50 EHIS. European Health Interview Survey (EHIS) Questionnaire 2006 [updated 2006; cited October 21, 2009] Available from: http://ec. europa.eu/health/ph_information/implement/wp/systems/docs/ ev_20070315_ehis_en.pdf

51 WHO. WHO-Five Well-being Index (WHO-5). [cited October 21, 2009] Available from: http://www.who-5.org/

52 RAND. MOS 36-Item Short Form Survey Instrument (SF-36). [cited October 21, 2009] Available from: http://www.rand.org/health/surveys_ tools/mos/mos_core_36item.html

53 RAND. Medical Outcomes Study: 12-Item Short Form Survey. [cited November 30, 2009] Available from: http://www.rand.org/health/ surveys_tools/mos/mos_core_12item.html

54 Sintonen H. 15-D instrument. [cited October 21, 2009] Available from: http://www.15d-instrument.net/15d

55 Bradley C. The Diabetes Treatment Satisfaction Questionnaire: DTSQ In: Bradley C, editor. Handbook of psychology and diabetes: a guide to psychological measurement in diabetes research and practice. Chur Switzerland: Harwood Academic Publishers; 1994: 111-132 